\title{
Early-season movement dynamics of phytophagous pest and natural enemies across a native vegetation-crop ecotone
}

\author{
S. Macfadyen ${ }^{a, *}$, J. Hopkinson $^{\text {b }}$, H. Parry ${ }^{c}$, M.J. Neave ${ }^{a}$, F.J.J.A. Bianchi ${ }^{\text {c,d }}{ }^{\text {, M.P. Zalucki }}{ }^{\text {e }}$, \\ N.A. Schellhorn ${ }^{c}$ \\ a CSIRO Agriculture Flagship, Black Mountain Laboratories, Acton ACT 2601, Australia \\ ${ }^{\mathrm{b}}$ Queensland Department of Agriculture, Fisheries, and Forestry, Toowoomba QLD 4350, Australia \\ ${ }^{\mathrm{C}}$ CSIRO Agriculture Flagship, Dutton Park QLD 4401 Australia \\ d Farming Systems Ecology, Wageningen University, Wageningen AN 6700, The Netherlands \\ e The University of Queensland, School of Biological Sciences, QLD 4072, Australia
}

\section{A R T I C L E I N F O}

\section{Article history:}

Received 8 April 2014

Received in revised form 9 November 2014

Accepted 11 November 2014

Available online 27 November 2014

\section{Keywords:}

Malaise trap

Interception trap

Biological control

Emigration

Landscape

Predator

Parasitoid

Spatial ecology

\begin{abstract}
A B S T R A C T
There is limited understanding about how insect movement patterns are influenced by landscape features, and how landscapes can be managed to suppress pest phytophage populations in crops. Theory suggests that the relative timing of pest and natural enemy arrival in crops may influence pest suppression. However, there is a lack of data to substantiate this claim. We investigate the movement patterns of insects from native vegetation (NV) and discuss the implications of these patterns for pest control services. Using bi-directional interception traps we quantified the number of insects crossing an $\mathrm{NV} /$ crop ecotone relative to a control crop/crop interface in two agricultural regions early in the growing season. We used these data to infer patterns of movement and net flux. At the community-level, insect movement patterns were influenced by ecotone in two out of three years by region combinations. At the functional-group level, pests and parasitoids showed similar movement patterns from NV very soon after crop emergence. However, movement across the control interface increased towards the end of the earlyseason sampling period. Predators consistently moved more often from NV into crops than vice versa, even after crop emergence. Not all species showed a significant response to ecotone, however when a response was detected, these species showed similar patterns between the two regions. Our results highlight the importance of NV for the recruitment of natural enemies for early season crop immigration that may be potentially important for pest suppression. However, NV was also associated with crop immigration by some pest species. Hence, NV offers both opportunities and risks for pest management. The development of targeted NV management may reduce the risk of crop immigration by pests, but not of natural enemies.
\end{abstract}

Crown Copyright $\odot 2014$ Published by Elsevier B.V. All rights reserved.

\section{Introduction}

While there is increasing recognition that phytophagous pest management based on the activity of predatory arthropods and parasitic wasps requires a landscape approach (Cronin and Reeve, 2005; Chaplin-Kramer and Kremen, 2012), the development of landscape-scale pest management strategies is still in its infancy (Schellhorn et al., 2008). Studies examining the relationship between landscape-scale features on pest suppression are becoming more common (Bennett and Gratton, 2012; CaballeroLópez et al., 2012; Chaplin-Kramer and Kremen, 2012). However,

\footnotetext{
* Corresponding author. Tel.: +61 262464432.

E-mail address: sarina.macfadyen@csiro.au (S. Macfadyen).
}

there is still limited understanding about which factors influence the spatial and temporal distribution of arthropod-mediated ecosystem services, and how these can be manipulated to suppress pests. The movement of pests and natural enemies is common (Rand et al., 2006; Thomson and Hoffmann, 2013), however we know little about the behavioural responses of arthropods to edges and ecotones. This movement is often described as the spillover of natural enemies from natural areas into cropping areas or vice versa (Rand et al., 2006). Understanding how landscape features may facilitate or impede movement can provide important information about immigration to crops and have implications for the management of arthropod-mediated ecosystem services (Kremen, 2005).

Agricultural landscapes can be considered as a collection of 'patches' with different land uses and disturbance levels. Crop 
habitats tend to be ephemeral, frequently disturbed, and recolonised throughout the growing season (Wissinger, 1997). In contrast, natural vegetation (NV) is more stable and can function as reservoirs of natural enemies (Bianchi et al., 2012; Letourneau et al., 2012), but potentially also of pests (Van Emden, 1965; Zhang et al., 2007; Al Hassan et al., 2013). Immigration from NV to crops involves the crossing of an ecotone, and species can have specific responses to different ecotones (Duelli et al., 1990; Duelli and Obrist, 2003). The contrast in vegetation types found on each side of an ecotone may be perceived differently by each species (Ries and Debinski, 2001). Therefore we cannot assume that all species will move easily from a remnant NV patch into a nearby crop. Quantifying the composition of the arthropod communities moving across a $\mathrm{NV} / \mathrm{crop}$ ecotone can provide novel insights into the function of these habitats in supporting pests and their natural enemies, and suggest which species can easily access resources in both these habitats.

The relative timing of pest and natural enemy arrival in crops is considered a key factor for the effectiveness of natural enemies in suppressing pest populations (e.g. Settle et al., 1996). Theory suggests that the timing of natural enemy arrival in crops can be influenced by the distance between the crop and source habitat (Bianchi et al., 2009), and the dispersal ability of natural enemies relative to that of the pests (Sivakoff et al., 2012). This implies that pest populations in crops far from natural enemy source habitats have an increased time window for unchecked build-up compared to crops near source habitats (Ekbom et al., 1992; Bianchi et al., 2010). However, empirical evidence of how timing of arrival is influenced by landscape context is scant (Petersen 1999; Alomara et al., 2002). Here, we use bi-directional interception traps to measure the activity of flying insects across the NV/crop ecotone, relative to a control crop/crop interface. In the early part of the cropping season, in two distinct agricultural regions, traps were placed on these different interfaces. Our aims are three-fold. Firstly, we characterise the insect community at the NV/crop ecotone relative to a control interface. Secondly, we assess the direction of movement across the ecotone, and use this to indicate whether NV is a net exporter of pests, predators or parasitoids during the early stage of the growing season. Thirdly, we explore species-specific behaviour across the ecotone and between two regions which have a different cropping season phenology.

\section{Methods}

Our study was conducted in two regions in Australia: a temperate and a sub-tropical region with both autumn-sown cereals. In both regions the field dimensions, crop-types and NV patches were mapped in a $7 \mathrm{~km}$ radius circular area using aerial images and ground-truthing. The temperate region in New South Wales (NSW) was located near the town of Young $(-34.422 \mathrm{~S}$, 148.460 E, Appendix A) and 16\% of the area consisted of NV dominated by Eucalyptus melliodora,E. macrocarpa, E. blakelyi, and Acacia spp. The crops included autumn-sown cereals and canola (25\%) interspersed with managed pastures (51\%). The sub-tropical region in Queensland (QLD) was located near the town of Pittsworth (-27.716 S, 151.635 E, Appendix A) and contained 15\% NV dominated by E. orgadophila, Acacia harpophylla and Casuarina cristata. This region had year-round cropping (21\%) that included autumn-sown cereals (wheat and barley) and, summer cropping (cotton and sorghum). Unmanaged pastures (19\%) and fallow land (43\%) were other important landscape elements.

\subsection{Sampling design}

Bi-directional flight interception traps (Southwood and Hendersen, 2000) were used to compare the direction and intensity of insect flight activity at the $\mathrm{NV} /$ crop ecotone relative to the crop/crop interface (Appendix A). These traps were used to measure the number of insects intercepted on both sides of the trap while they were flying from one habitat patch to another over weekly periods. The data were used to make inferences about the movement patterns at the community, functional group and taxon level. Within each region there were six trapping sites: three ecotone sites and three control interfaces. The location of each trapping site was independent in terms of not sharing field boundaries with other sites. The straight-line distance between sites ranged from $\sim 500 \mathrm{~m}$ to $8 \mathrm{~km}$ (Appendix B). In 2010, cereal fields consisted of wheat in NSW and either wheat (two sites) or barley (four sites) in QLD; in 2011 all fields were wheat.

There were six traps per region, and each trap had two collection bottles (on each side of the trap), therefore there were 24 samples per time period. At each time period the bottles were open for 5-8 days. Sampling commenced at cereal crop planting and continued over two winter cropping seasons; QLD July-November 2010 and July-August 2011, NSW May-November 2010 and May-August 2011. Samples were collected every two weeks for 5-8 sample periods (QLD 9 - 2010 and 5 - 2011, NSW $8-2010$ and $8-2011$ ), giving a total of 360 samples. Two samples (both in NSW) were discarded because the trap was damaged by cattle. Samples were labelled as "NV" (NV/crop ecotone, insects moving from NV into crops), "crop" (NV/crop ecotone, insects moving from the crop and entering NV), or "control" (crop/crop, insects moving from a crop field to another crop). The samples of the crop/crop interface consisted of insects moving between crops from both directions and received the same label. Therefore, there was double the number of samples at each time point for the control than for either the NV or crop treatments.

As there was large variation in crop growth development rates between the two regions it was necessary to standardise the sampling dates to ensure we were focussing only on the samples collected in the early-season growth period of the crop. Growth Degree Days (GDD) at each site was calculated using the equation:

$\mathrm{GDD}=\frac{\left(T_{\max }+T_{\min }\right)}{2}-T_{\text {base }}$

where $T_{\max }$ is the daily maximum temperature, $T_{\min }$ is the daily minimum temperature and $T_{\text {base }}$ was set at $0^{\circ} \mathrm{C}$. When temperatures were below $0^{\circ} \mathrm{C}, T_{\min }$ was converted as $T_{\min }=T_{\text {base }}$ (McMaster, 1997). Temperature data were collected from nearby weather stations to calculate GDD. Daily GDD value from the date of crop planting was summed to provide an accumulated GDD value (referred to as AGDD hereafter). When no information on the planting date was available, this date was estimated as 10 days prior to crop emergence. AGDD was used as a proxy for time and then to select samples to analyse that were within 0-900 AGDD (this reduced the total number of samples from 360-211). AGDD values between 0-900 were considered in the early stage of crop development as this roughly corresponds to the period up to stem elongation of cereal crops.

\subsection{Insect sampling}

The bi-directional interception traps (Sante Traps, Lexington, $\mathrm{KY}$ ) were made out of fine mesh material and had a black mid-vane (165 cm length, $178 \mathrm{~cm}$ height at front, $104 \mathrm{~cm}$ height at back) that functioned as an interception trap. One end was supported with a tent pole and had two collection bottles half filled with $70 \%$ ethanol ( $\sim 250 \mathrm{ml}$ and $\sim 5 \mathrm{ml}$ of detergent). Insects flying from one direction hit the mid-vane and climbed upwards entering the collection bottle, while insects flying from the other direction were captured on the opposite side (Appendix A). Traps were positioned along the ecotone or control interface regardless of prevailing wind 
direction. Certain flying insect species (e.g. honeybees) can avoid this trap, and are captured in very low numbers. Therefore, we draw no conclusions about those species here.

Each sample was returned to the laboratory, sieved through a fine mesh strainer $(0.5 \mathrm{~mm})$, and the remaining insects sorted under a stereo microscope (10-50× magnification). Grain pests and their natural enemies were counted and identified (Bailey, 2007). This species list included (but was not limited to) important aphid pests (Aphidae), ladybeetle adults (Coccinellidae), hoverfly adults (Syrphidae), brown lacewing adults (Micromus sp.), and a range of parasitic wasps identified to genus (Appendix B). Adult Lepidoptera (moths and butterflies) were excluded because these

Table 1

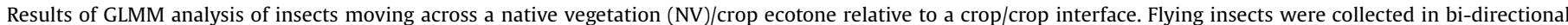

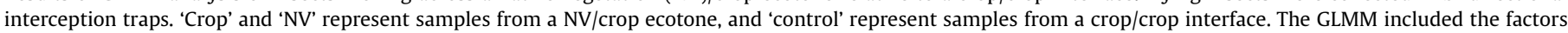

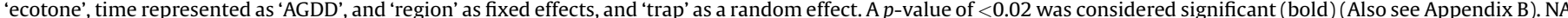

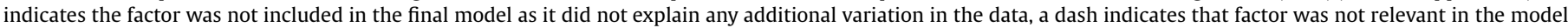
(e.g. 'region' term not necessary when species only collected in one region).

\begin{tabular}{|c|c|c|c|c|c|c|c|c|c|c|}
\hline & Taxa & $\begin{array}{l}\text { Distribution } \\
\text { used in model }^{\mathrm{e}}\end{array}$ & Ecotone & AGDD & Region & $\mathrm{AGDD}^{2}$ & $\begin{array}{l}\text { Int } \\
(\text { ecotone } \times \text { AGDD })\end{array}$ & $\begin{array}{l}\text { Int } \\
(\text { ecotone } \times \text { region })\end{array}$ & $\begin{array}{l}\text { Int } \\
(A G D D \times \text { region })\end{array}$ & $\begin{array}{l}\text { Matches hypothetical } \\
\text { model no. }\end{array}$ \\
\hline & $\begin{array}{l}\text { Pest functional } \\
\text { group }\end{array}$ & NB2 & $<\mathbf{0 . 0 0 1}$ & $<\mathbf{0 . 0 0 1}$ & $<\mathbf{0 . 0 0 1}$ & NA & 0.08342 & NA & $<\mathbf{0 . 0 0 1}$ & 7 \\
\hline & $\begin{array}{l}\text { Predator } \\
\text { functional group }\end{array}$ & NB2 zi & $<\mathbf{0 . 0 0 1}$ & 0.729 & $<\mathbf{0 . 0 0 1}$ & NA & NA & NA & $<\mathbf{0 . 0 0 1}$ & 3 \\
\hline & $\begin{array}{l}\text { Parasitoid } \\
\text { functional group }\end{array}$ & NB2 & $<\mathbf{0 . 0 0 1}$ & $<\mathbf{0 . 0 0 1}$ & $<\mathbf{0 . 0 0 1}$ & NA & 0.0038 & NA & $<\mathbf{0 . 0 0 1}$ & 8 \\
\hline \multicolumn{11}{|c|}{ Both regions (multiple years) } \\
\hline \multirow[t]{4}{*}{ Pests } & $\begin{array}{l}\text { Acyrthosiphon } \\
\text { spp. }{ }^{c}\end{array}$ & NB2 & 0.013 & $<\mathbf{0 . 0 0 1}$ & $<\mathbf{0 . 0 0 1}$ & NA & 0.0100 & $<\mathbf{0 . 0 0 1}$ & $<\mathbf{0 . 0 0 1}$ & 8 \\
\hline & $\begin{array}{l}\text { Rhopalosiphum } \\
\text { padi }\end{array}$ & NB2 & 0.002 & 0.001 & $<\mathbf{0 . 0 0 1}$ & NA & NA & NA & $<\mathbf{0 . 0 0 1}$ & 7 \\
\hline & $\begin{array}{l}\text { Rhopalosiphum } \\
\text { rufiabdominalis }\end{array}$ & NB2 & 0.002 & $<\mathbf{0 . 0 0 1}$ & 0.007 & NA & 0.0080 & NA & 0.0305 & 8 \\
\hline & Nysius vinitor & NB2 & 0.048 & 0.253 & 0.001 & 0.0531 & 0.1257 & NA & 0.0044 & 1 \\
\hline \multirow[t]{3}{*}{ Predators } & Micromus sp. & NB2 zi & 0.061 & 0.537 & $<\mathbf{0 . 0 0 1}$ & NA & NA & NA & No & 1 \\
\hline & $\begin{array}{l}\text { Melangyna } \\
\text { (Austrosyrphus) } \\
\text { sp. }\end{array}$ & NB2 & $<0.001$ & 0.479 & $<0.001$ & NA & NA & NA & $<0.001$ & 3 \\
\hline & $\begin{array}{l}\text { Coccinellidae } \\
\text { multiple species }\end{array}$ & NB1 & 0.076 & 0.026 & 0.004 & NA & NA & 0.2579 & No & 1 \\
\hline \multirow[t]{4}{*}{ Parasitoids } & Diadegma sp. B. & $\mathrm{P}$ & 0.025 & 0.439 & 0.064 & NA & NA & NA & $<\mathbf{0 . 0 0 1}$ & 1 \\
\hline & Microgastrinae & NB2 & 0.317 & 0.185 & 0.024 & NA & NA & NA & $<\mathbf{0 . 0 0 1}$ & 1 \\
\hline & Netelia sp. & NB1 zi & $<\mathbf{0 . 0 0 1}$ & $<\mathbf{0 . 0 0 1}$ & $<\mathbf{0 . 0 0 1}$ & NA & 0.0791 & NA & 0.0011 & 7 \\
\hline & Aphidiinae & NB2 & 0.020 & 0.239 & $<0.001$ & NA & 0.0153 & NA & 0.0011 & 4 \\
\hline \multicolumn{11}{|c|}{ Both regions (only one year) } \\
\hline \multirow[t]{2}{*}{ Pests } & $\begin{array}{l}\text { Rhopalosiphum } \\
\text { maidis }\end{array}$ & NB2 & $<\mathbf{0 . 0 0 1}$ & 0.061 & $<\mathbf{0 . 0 0 1}$ & NA & 0.4619 & NA & 0.0018 & 3 \\
\hline & $\begin{array}{l}\text { Therioaphis } \\
\text { trifolii }^{\mathrm{d}}\end{array}$ & NB2 zi & 0.001 & 0.006 & $<\mathbf{0 . 0 0 1}$ & NA & 0.0131 & 0.0614 & $<\mathbf{0 . 0 0 1}$ & 8 \\
\hline \multicolumn{11}{|l|}{ NSW only } \\
\hline \multirow[t]{2}{*}{ Pests } & $\begin{array}{l}\text { Creontiades } \\
\text { dilutus }\end{array}$ & NB1 & 0.885 & 0.057 & - & NA & NA & - & - & 1 \\
\hline & Myzus persicae & NB2 & 0.107 & 0.004 & - & NA & 0.2603 & - & - & 5 \\
\hline Predators & Nabis kinbergii & P zi & 0.903 & 0.611 & - & NA & No & - & - & 1 \\
\hline Parasitoids & $\begin{array}{l}\text { Ichneumon } \\
\text { promissorius }\end{array}$ & $\mathrm{P}$ & $<\mathbf{0 . 0 0 1}$ & 0.011 & - & 0.0292 & 0.039 & - & - & 7 \\
\hline \multicolumn{11}{|l|}{ QLD only } \\
\hline \multirow[t]{4}{*}{ Pests } & $\begin{array}{l}\text { Green sow thistle } \\
\text { aphid }\end{array}$ & P zi & 0.591 & 0.005 & - & NA & NA & - & - & 5 \\
\hline & $\begin{array}{l}\text { Brown sow thistle } \\
\text { aphid }^{\text {a }}\end{array}$ & NB2 & 0.950 & 0.050 & - & 0.108 & NA & - & - & 1 \\
\hline & $\begin{array}{l}\text { Metopolophium } \\
\text { dirhodum }\end{array}$ & NB2 & 0.411 & 0.216 & - & 0.010 & NA & - & - & 1 \\
\hline & $\begin{array}{l}\text { jassids } \\
\text { (leafhoppers) }^{\mathrm{b}}\end{array}$ & linear $(\log 10)$ & $<\mathbf{0 . 0 0 1}$ & 0.011 & - & 0.0119 & NA & - & - & 7 \\
\hline \multirow[t]{4}{*}{ Predators } & Mallada sp. & $\mathrm{P}$ & 0.518 & 0.088 & - & NA & NA & - & - & 1 \\
\hline & $\begin{array}{l}\text { Rove beetles } \\
\text { (Staphylinidae) }\end{array}$ & NB1 zi & 0.160 & 0.015 & - & 0.0282 & 0.0946 & - & - & 5 \\
\hline & $\begin{array}{l}\text { Simosyrphus } \\
\text { grandicornis }\end{array}$ & NB2 & 0.649 & 0.019 & - & NA & 0.2381 & - & - & 5 \\
\hline & $\begin{array}{l}\text { Sphaerophoria } \\
\text { macrogaster }\end{array}$ & NB2 & 0.730 & $<\mathbf{0 . 0 0 1}$ & - & NA & 0.2449 & - & - & 5 \\
\hline
\end{tabular}

\footnotetext{
a Interaction between AGDD $\times \mathrm{AGDD}^{2} \mathrm{P}=0.0191$.

b Interaction between $\mathrm{AGDD} \times \mathrm{AGDD}^{2} \mathrm{P}=0.050$.

c Interaction between ecotone $\times$ AGDD $\times$ region $P=0.025$.

d Interaction between ecotone $\times$ AGDD $\times$ region $P=0.034$.

e The GLMM model distributions included negative bionimal 1 and 2 (NB1, NB2) or Poisson (P), with zero inflation (zi).

${ }^{f}$ Refers to the hypothetical models outlined in Appendix B, Table 1.
} 
specimens cannot accurately be identified in ethanol. Each taxon was grouped into one of three functional groups: pests, predators or parasitoids (Appendix B).

\subsection{Data analysis}

The composition of the insect community at the ecotone and control interface was visualised using non-metric multidimensional scaling (NMDS) in PRIMER 6 (v 6.1.13) (Clark and Gorley, 2006). A matrix of total abundance of each taxon found in each treatment (NV, crop, control) was constructed for each year (2010, 2011) and region (NSW, QLD) for a total of four matrices. Abundance was square-root transformed (to down-weight common species) and a Bray Curtis (also known as Sorensen) similarity matrix was created. A randomization test was used to assess the optimal number of dimensions for NMDS ordination. A permutational analysis of variance using PERMANOVA+ (v 1.0.3) (Anderson et al., 2008) was used to test for differences in community composition between ecotone and control. Type III partial sums of squares were derived with Monte Carlo simulations involving the unrestricted permutation of the raw data (9999 permutations). Pair-wise comparisons were then made between replicates of the NV, crop and control treatments. Comparisons with $P(\mathrm{MC})<0.1$ were considered significant. For the cases where significant community structuring was found, the taxa were separated into functional groups (pests, predators and parasitoids) and the analysis repeated at this finer resolution.

\section{A. NSW 2010, 32 taxa, $P(M C)=0.0039$}

Transform: square root Resemblance: S17 Bray Curtis similarity

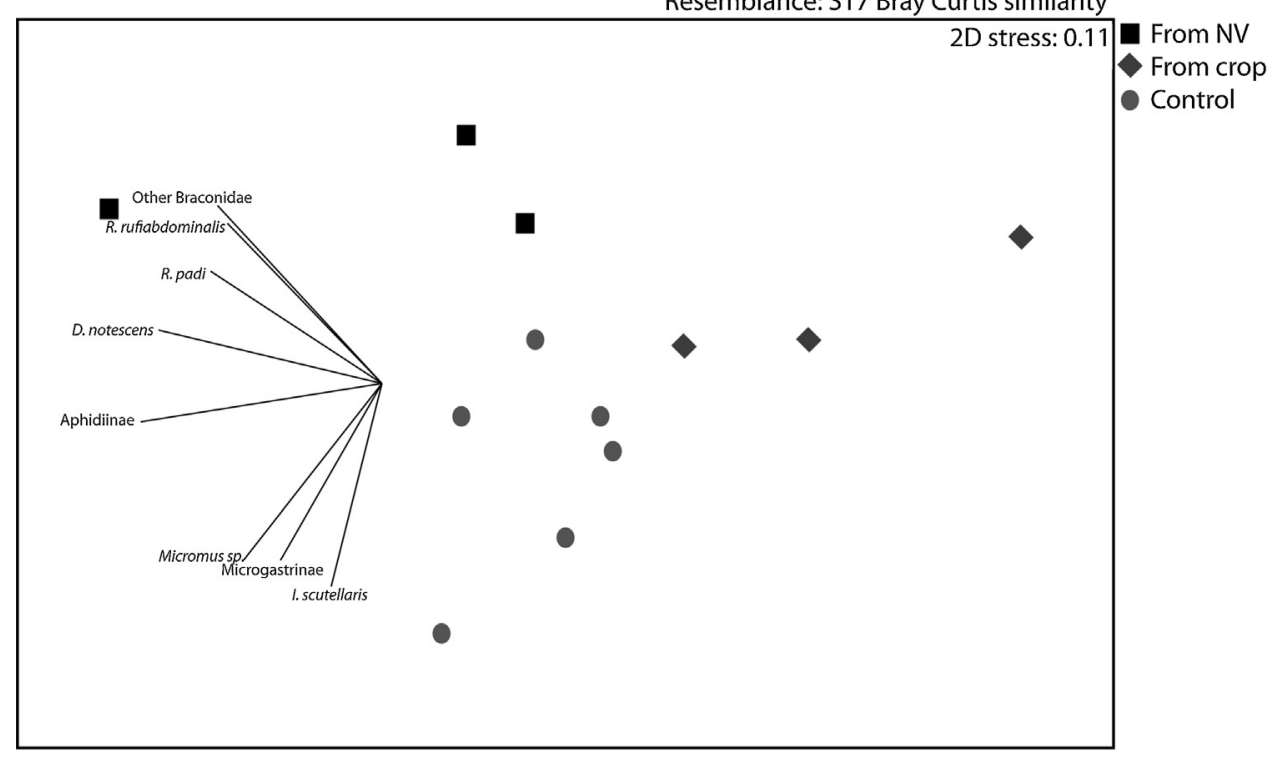

B. QLD 2011, 39 taxa, $P(M C)=0.020$

Transform: square root Resemblance: S17 Bray Curtis similarity

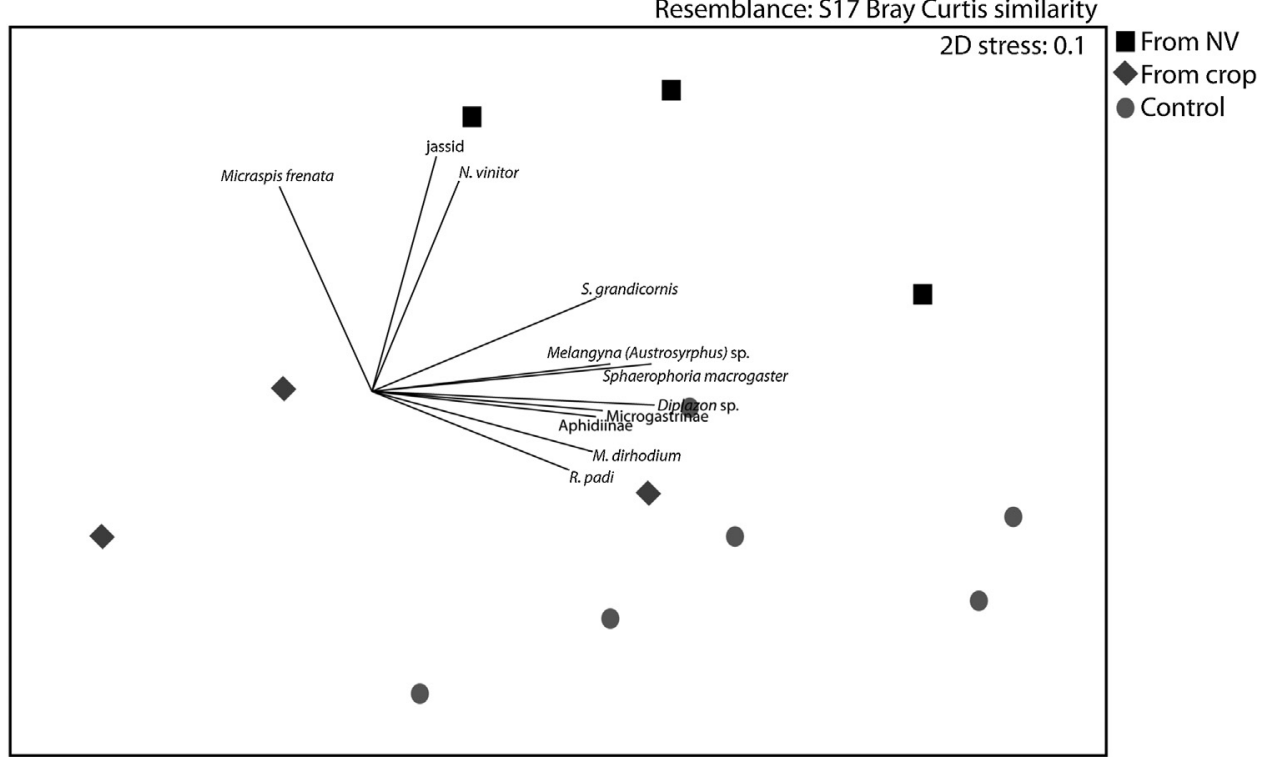

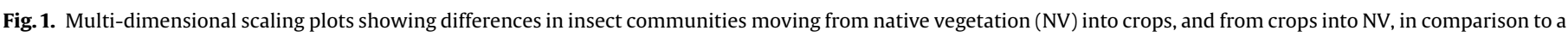

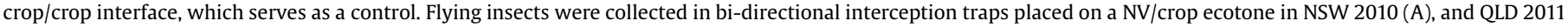

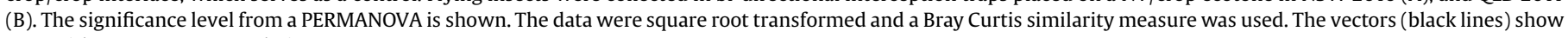
taxa with a Spearman correlation $>0.7$. 
Prior to NMDS analysis each of the four matrices were tested for spatial autocorrelation of samples using a combination of similarity measures and regression analysis to test whether the composition of insect communities were related to the proximity of traps (Appendix C). Some degree of spatial autocorrelation was observed in the QLD 2010 samples and these samples were therefore discarded for the NMDS analysis (Appendix C).

A. Pests, $P(M C)=0.17$

Transform: square root

Resemblance: S17 Bray Curtis similarity

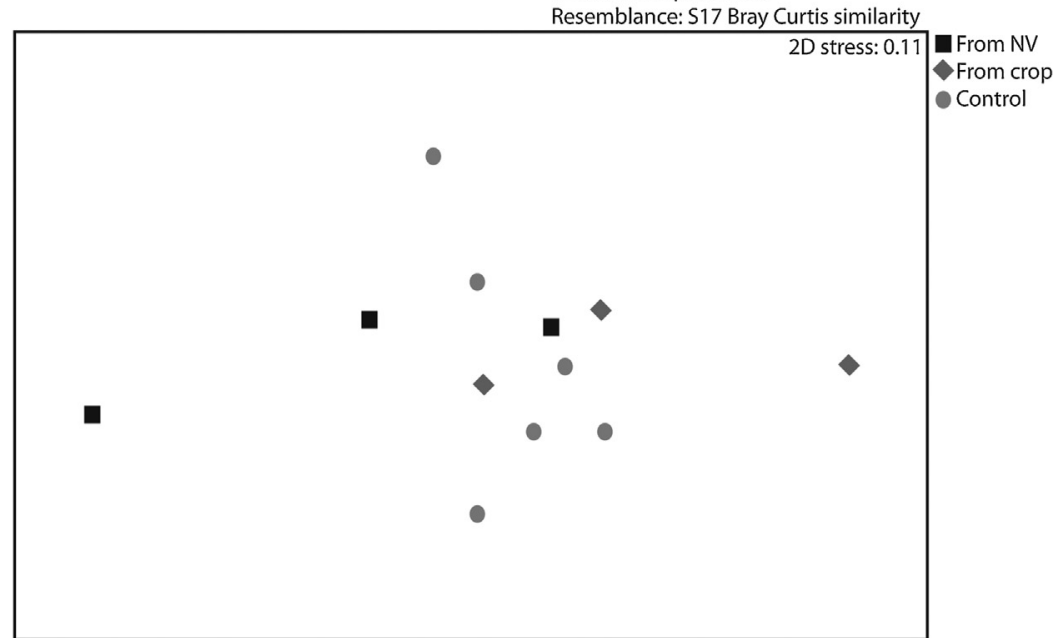

B. Predators, $P(M C)=0.0007$

Transform: square root Resemblance: S17 Bray Curtis similarity

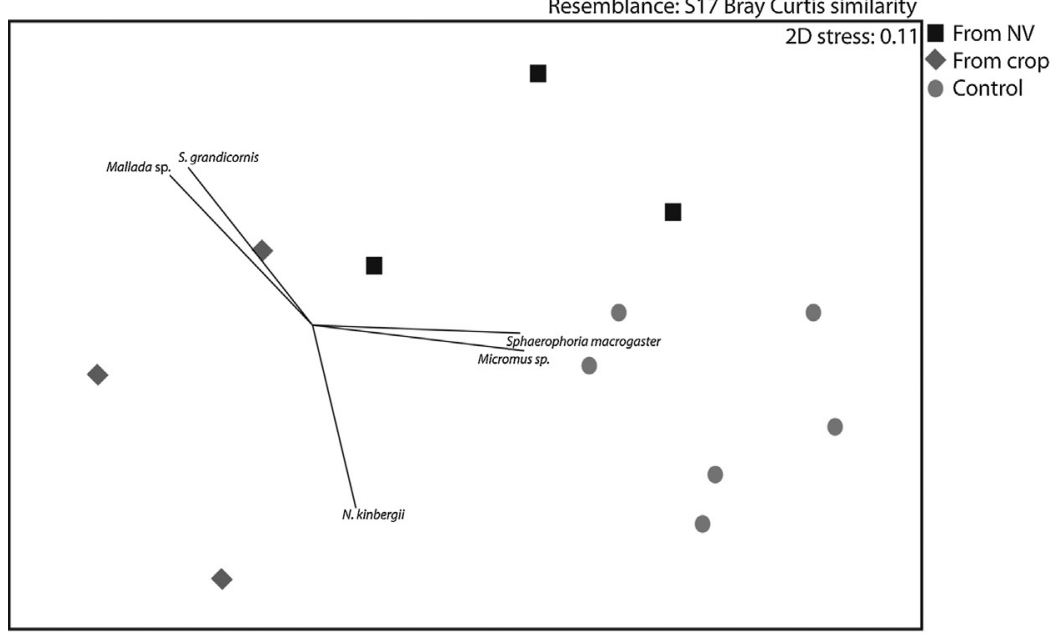

C. Parasitoids, $P(M C)=0.0023$

Transform: square root

Resemblance: S17 Bray Curtis similarity

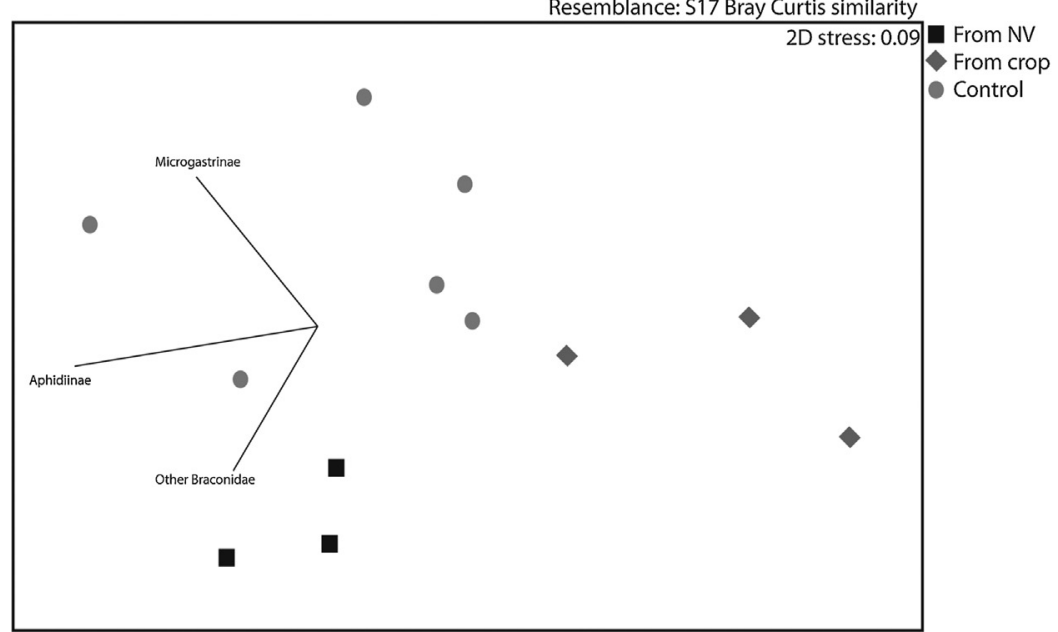

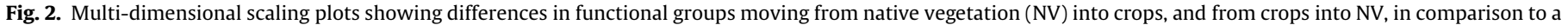

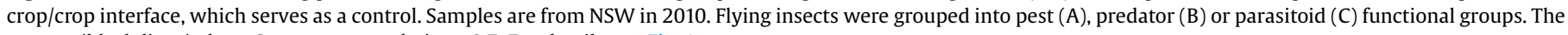
vectors (black lines) show Spearman correlation $>0.7$. For details see Fig. 1 . 
A series of generalised linear mixed effects models (GLMM) were used to test hypotheses regarding the movement of functional groups and individual taxa in relation to ecotone (Appendix C). The glmmADMB package in $\mathrm{R}$ ( $\mathrm{v}$ 2.15.0) was used to develop a range of GLMM as basic linear regression models following Bolker et al. (2009, 2011),). $\log _{10}$ transformation of the response variables rarely resulted in normally distributed data (except for jassids in QLD, Table 1). Therefore, each untransformed response variable was included in the full model. Fixed effects were 'ecotone' (NV, crop, or control), time expressed as the 'AGDD' value (0-900), and 'region' (NSW, QLD). A random effect 'trap' was included in every model to account for the non-independence of repeated measures over time. The interactions between the three fixed effects were included in the full model, and later excluded if not significant (based on AIC). An additional fixed effect quadratic term $\left(\mathrm{AGDD}^{2}\right)$ was introduced into the models to improve the fit. The response variables consisted of the abundance of the three functional groups (pests, predators and parasitoids) or individual taxon (species or genera). A cumulative count of 10 specimens per taxon was used as the criterion for inclusion in the analysis. Inferences about the fixed model parameters were made using the 'Anova' function in the 'car' package (Fox and Weisberg, 2011), which produces an analysis of deviance with chi-square type II tests. A conservative $p$-value $(<0.02)$ for ecotone effects was used to assess significance. Using the final model, we derived region and ecotone specific predictions of insect movement across time (AGDD between 0 and 900). Each GLMM represented a hypothesis regarding the amount of movement across the ecotone relative to the control and the direction of movement across the ecotone (Appendix C). For those species that showed a significant ecotone effect the predicted mean numbers moving across the ecotone and control (averaged across the whole sampling period) was ranked. The raw data from each sample for the three main functional groups is shown in Appendix D.

\section{Results}

The 211 analysed samples contained 7406 pest, 2861 predator, and 1689 parasitoid individuals. The average number of taxa per sample was $24 \pm 1$ SEM, and ranged from 13 to 43 taxa. The community-level analyses suggest that the insect communities moving across the control interface were different to those moving across the ecotone, however this pattern was only observed in two out of three cases. NMDS plots showed three clearly separate clusters in NSW 2010, suggesting that insect communities moving from NV were different to communities moving from the crop or between crop/crop interfaces (Fig. 1a). Similar clustering of insect communities was observed in QLD in 2011 (Fig. 1b), but not in NSW 2011 (data not shown). The lack of structuring in the QLD 2010 samples is confounded by some spatial autocorrelation of samples and were therefore discarded from this analysis (Appendix B). NSW and QLD had region-specific taxa that were influential in the formation of the clustering pattern; only the oat aphid Rhopalosiphum padi, Aphidiinae parasitoids and Microgastrinae parasitoids were abundant in both NSW and QLD (Fig. 1). The PERMANOVA analysis supported the structuring of the ordination pattern according to ecotone in NSW $2010(P(\mathrm{MC})=0.0039)$ with significant differences between $\mathrm{NV}$ and control $(P(\mathrm{MC})=0.025)$, and crop and control $(P(M C)=0.026)$, and a marginally significant difference between NV and crop $(P(M C)=0.062)$. For QLD 2011 $(P(\mathrm{MC})=0.020)$ there was a marginally significant difference between NV and control $(P(\mathrm{MC})=0.072)$, and crop and control $(P(\mathrm{MC})=0.058)$, and a non-significant difference between NV and crop $(P(M C)=0.11)$. These results demonstrate that in both these cases the communities moving across the $\mathrm{NV} /$ crop ecotone were different from those moving across the crop/crop interface.

\subsection{Functional group response to ecotone}

Cases with a significant ecotone effect at the whole communitylevel were further explored by placing taxa into functional groups. For NSW 2010 we found significant clustering in relation to movement across the ecotone for the predators and parasitoids, but not for pests (Fig. 2). All pair-wise comparisons were significant for predators (NV and control $P(\mathrm{MC})=0.031$, NV and crop $P(\mathrm{MC})=0.047$, crop and control $P(\mathrm{MC})=0.002$ ) and parasitoids (NV and control $P(\mathrm{MC})=0.029$, NV and crop $P(\mathrm{MC})=0.022$, crop and control $P(\mathrm{MC})=0.021$ ). The movement of damsel bugs (Nabis kingbergii) was influential for the ordination of samples along the vertical axis (separating samples moving from NV from those moving from crop and control), and the brown lacewing (Micromus sp.) along the horizontal axis (separating samples moving from NV and control from those moving from crop) (Fig. 2b). In the parasitoid functional group, five out of six of the controls had a higher abundance of Microgastrinae (in comparison to NV, Fig. 2c). The presence of higher numbers of Aphidiinae contributed to the separation of samples along the horizontal axis (Fig. 2c). In QLD 2011, pests showed significant structuring $(P(M C)=0.0078)$, but the structuring of predators $(P(M C)=0.092)$ and parasitoids $(P(\mathrm{MC})=0.065)$ was only marginally significant.

GLMMs were used to estimate the relationship between ecotone, region and time (AGDD), for the response taxa (species and species functional groups). For all three functional groups, the GLMMs indicated that there is a significant interaction between time (AGDD) and region, thus overall movement patterns of insects across time differed between the two regions (Table 1 ). In general, the movement of insects across the ecotone decreased in time in NSW, whereas it increased in time in QLD. However, we did find a consistent ecotone effect across the regions. For predators there was a consistently greater movement from NV into crops as compared to the control, and no interaction with time was detected (Fig. 3, Table 1). For parasitoids, the pattern was more complex, with clear regional differences in response to ecotone across the early season period (Fig. 4, Table 2). In NSW and QLD movement from $\mathrm{NV}$ was greater than the control between 0 and
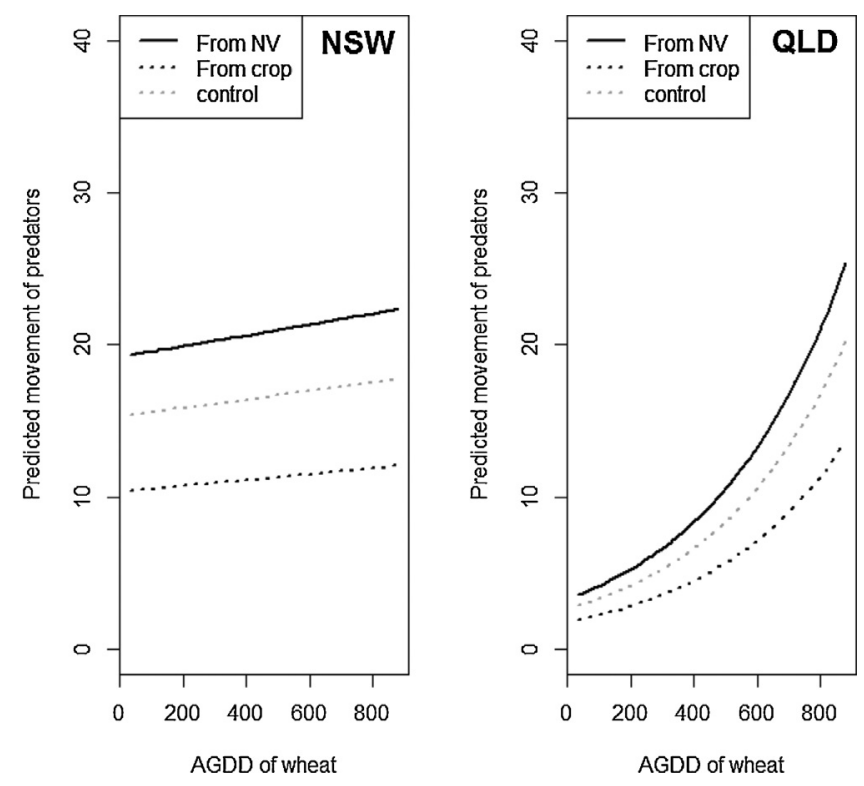

Fig. 3. Movement patterns of insect predators across a NV/crop ecotone in comparison to a control interface. 'From NV' indicates insects moving from NV patches into cereal fields, 'From crop' are insect moving from cereal fields into NV patches, 'control' are the insects moving across a crop/crop interface. AGDD (accumulated growth degree days of wheat) is used as a measure of time. Back transformed predicted values from a GLMM are indicated by lines (Table 2). 

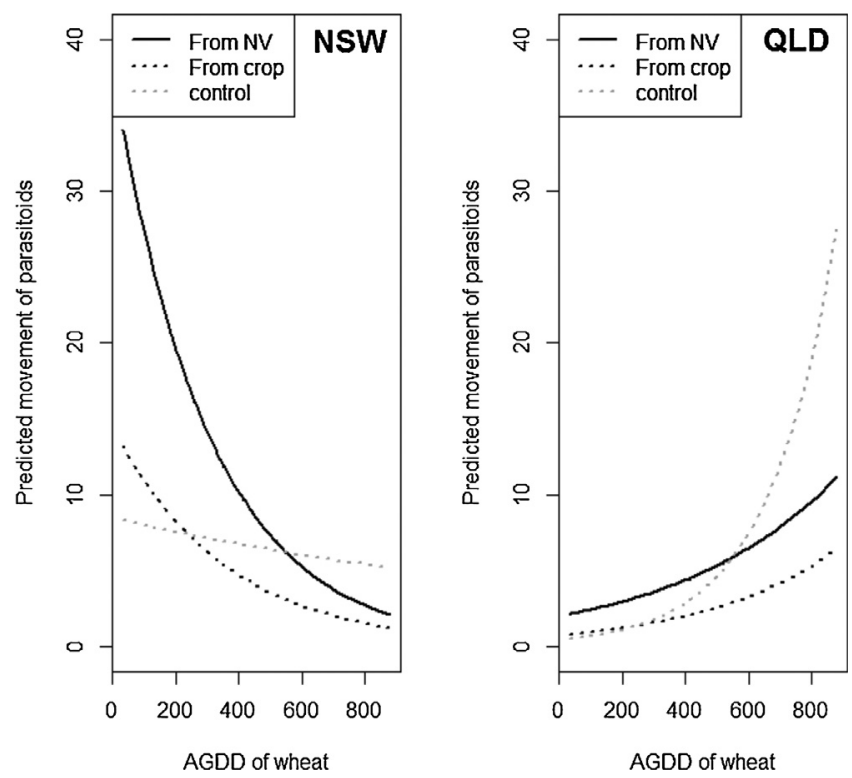

Fig. 4. Movement patterns of parasitoids across a NV/crop ecotone in comparison to a control interface. AGDD (accumulated growth degree days of wheat) is used as a measure of time. For details see Fig. 3.

$\sim 550$ AGDD, but in QLD movement across the control interface increased rapidly hereafter. In NSW pest movement from NV was higher between 0 and 600 AGDD, however after 600 AGDD there was little movement across both the ecotone and the control interface (Fig. 5, Table 2). In QLD the overall predicted values for pests suggest that movement from $\mathrm{NV}$ is higher than for the control for up to $\sim 650$ AGDD (Fig. 5, Table 2).

\subsection{Species-specific response to ecotone}

Individual taxa varied greatly in their response to ecotone (Table 1). For many taxa the GLMMs showed a significant region effect, and significant interaction between region and time (AGDD), and mostly a non-significant interaction between ecotone and region (Table 1 ). This suggests that whilst there are differences between the two regions in the extent of movement over time, a consistent pattern was observed in relation to ecotone. Out of the 25 taxa analysed, there was no significant ecotone effect for 15 taxa (Table 1 ), suggesting that these species exhibit similar movement dynamics across the ecotone and control interface. If we just consider the taxa that were common in the traps in both regions then eight out of 13 taxa showed no significant ecotone effect (Table 1).
For most taxa there was a significant region effect (11 out of 13 taxa collected across both regions, Table 1 ), but this was not always related to the ecotone. For example, Micromus sp. showed much greater movement across both the ecotone and the control interface in NSW than in QLD at the same crop stage (Table 1). For the taxa whose movement patterns were significantly affected by ecotone (Table 2 ), the conclusions for each region were generally the same. The only exception were Aphidiinae parasitoids that showed more movement relative to the control from NV in NSW, but not in QLD (Table 2). Movement from NV was more prevalent for the parasitic wasp genus Netelia and the predatory Melangyna than vice versa, but not for the parasitic wasp Ichneumon promissorius. The pest aphids $R$. padi and $R$. rufiabdominalis showed greater movement from NV relative to the control, but Acyrthosiphon spp., R. maidis and Therioaphis trifolii did not (Table 2).

\section{Discussion}

Firstly at the community-level ecotones influence the movement of predators and parasitoids, and to lesser extent pests during the critical early-stage period. Secondly, predators were found to consistently move more frequently from NV towards crops (relative to the control) throughout the entire early-season period. Finally, whilst movement patterns across time differed for each region, the species-specific responses to ecotone were similar across the two regions. In theory, the relative timing of pests and natural enemies arriving in crop fields early in the season may influence pest population build-up and ultimately pest control (Ekbom et al., 1992; Ives and Settle, 1997; Chang and Kareiva, 1999). Overall, we found no time lag between the movement of pests and natural enemies into crop fields from NV. If the theoretical predictions about the timing of arrival hold, these crop fields should be well placed to suppress pest populations throughout the season.

\subsection{Insect communities moving across the ecotone}

There is a high contrast between NV and the adjacent crop fields in terms of vegetation structure and composition, which may limit movement across this ecotone for certain species (Ries and Debinski, 2001; Cunningham et al., 2013). Campbell et al. (2011) used flight interception traps to show that the movement of beetles across two ecotones with different degrees of contrast varied considerably. In the light of these results it is not surprising that we found significant differences between the insect communities moving across the ecotone and those moving across the crop/crop interface in NSW 2010 and QLD 2011. In NSW 2010, the

\section{Table 2}

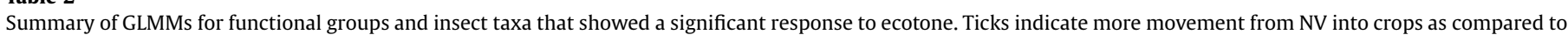

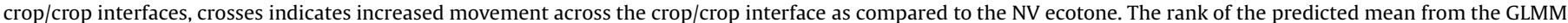
(Table 1 ) is provided for the entire sampling period (B) or part of the sample period (C) (see also Appendix B).

\begin{tabular}{|c|c|c|c|c|c|}
\hline & Taxa & Predicted values mean rank NSW & Conclusion NSW & Predicted values mean rank QLD & Conclusion QLD \\
\hline B & Pest functional group & NV > crop > control & レ & NV > control > crop & レ (But control similar) \\
\hline B & Predator functional group & $\mathrm{NV}>$ control $>$ crop & レ & $\mathrm{NV}>$ control $>$ crop & $\nu$ \\
\hline C & Parasitoid functional group & $0-600:$ NV $>$ crop $>$ control & レ & $0-500: \mathrm{NV}>$ control $>$ crop & レ \\
\hline C & Acyrthosiphon spp. & 400-900: control $>\mathrm{NV}=\mathrm{crop}$ & $\mathbf{x}$ & 300-900: control $>$ crop $>N V$ & $\mathbf{x}$ \\
\hline B & Rhopalosiphum padi & $\mathrm{NV}>$ control $>$ crop & $\nu$ & $\mathrm{NV}>$ control $>$ crop & $\nu$ \\
\hline $\mathrm{C}$ & Rhopalosiphum rufiabdominalis & 0-600: NV > crop > control & レ & $0-600: \mathrm{NV}>$ crop $>$ control & レ \\
\hline B & Rhopalosiphum maidis & Control $>$ crop $>$ NV & $x$ & Control $>$ NV $>$ crop & $\mathbf{x}$ \\
\hline C & Therioaphis trifolii & $0-200:$ NV > control $>$ crop & $x$ & 0-900: control $>\mathrm{NV}>$ crop & $x$ \\
\hline B & Melangyna (Austrosyrphus) sp. & $\mathrm{NV}>$ control $>$ crop & $\boldsymbol{V}$ (But control similar) & NV $>$ control $>$ crop & $\boldsymbol{V}$ (But control similar) \\
\hline B & Netelia sp. & NV $>$ crop $>$ control & レ & $\mathrm{NV}>\mathrm{crop}=$ control & レ \\
\hline C & Aphidiinae & 0-450: NV > crop > control & $\nu$ & 400-900: control $>$ NV > crop & $x$ \\
\hline B & Ichneumon promissorius & Control $>$ crop $>$ NV & $x$ & - & - \\
\hline B & Jassids (leafhoppers) & - & - & NV $>$ control $>$ crop & $\boldsymbol{\nu}$ \\
\hline
\end{tabular}



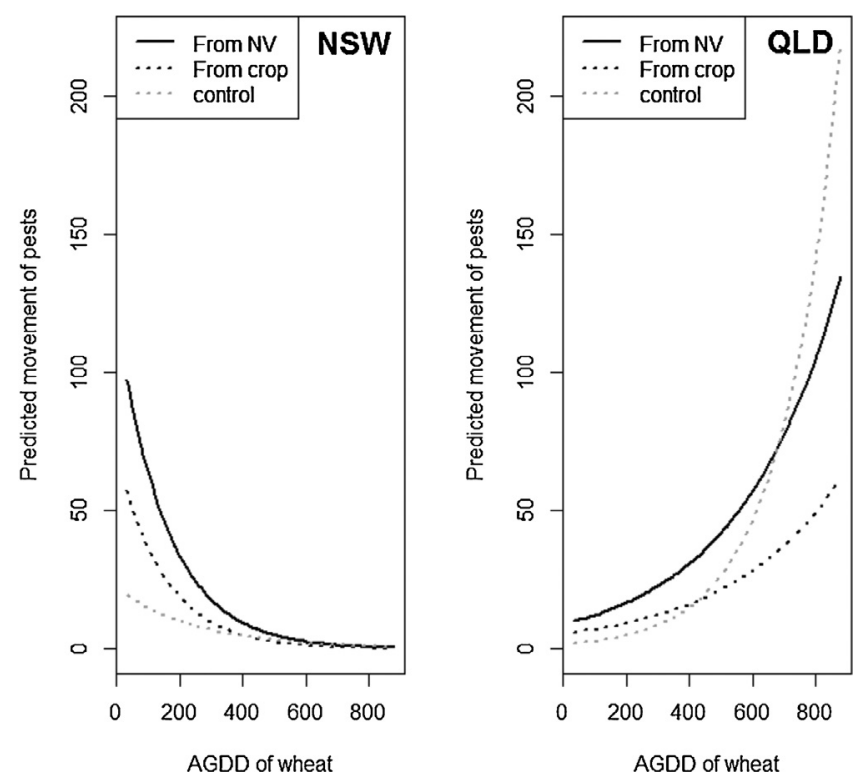

Fig. 5. Movement patterns of pests across a NV/crop ecotone in comparison to a control interface. AGDD (accumulated growth degree days of wheat) is used as a measure of time. For details see Fig. 3.

natural enemy communities showed clearer differences in response to ecotone than the pest communities. Given that many species rely on resources that can only be found in $\mathrm{NV}$ at this time of the year, one may anticipate differences in insect movement patterns between the ecotone and the control interface. Indeed, there are many species whose presence or abundance is influenced by the amount of natural and semi-natural areas in agricultural landscapes (Duelli and Obrist, 2003). In a literature review, Chaplin-Kramer and Kremen (2012) found that generalist natural enemies showed a positive response to landscape complexity (and the area of semi-natural habitats), while pests did not. Synthesising these findings with the results of our study suggest that natural enemies are more likely to forage for resources in and around NV than pests, and that natural enemies may therefore benefit more from NV than pests.

\subsection{Native vegetation as a net exporter of pests, predator and parasitoids}

At crop planting during autumn, the vegetation in our study sites consisted of semi-perennial pastures and small NV patches (Appendix A). As bare fields provide little refuge and resources, the potential sources for insects are limited to a few habitat patches. At the functional group level we observed large numbers of predators moving from NV into the crop suggesting that predators are emigrating from NV. These patterns were consistent throughout the early season period. For parasitoids, the pattern was more complex, with more movement from NV very early in the sampling period in NSW (up to 550 AGDD) than between the crop/crop interface. Later in the sampling period, NV still provided immigrants, but movement across the crop/crop interface outnumbered that of the ecotone (Fig. 4). This suggests that parasitoids may be better able to find suitable hosts in the crop fields because of higher host densities and a simpler vegetation structure (Vollhardt et al., 2008; Macfadyen and Muller, 2013). The pest functional group showed more movement from NV early in the cropping season (up to 650 days). However, the significant effect of time and region suggests that movement patterns change across this early season time period, probably in response to the stage of the crop (Mesa et al., 2013). A better understanding of the plant-pest-natural enemy relationships (Stephens et al., 2006; Isaacs et al., 2009) may lead to management strategies that facilitate the movement of natural enemies, but impede that of pests.

\subsection{Species-specific ecotone movement behaviours}

Not all pest and natural enemy species were equally likely to be captured in the interception traps (Irwin et al., 2000). Therefore, only those species with directional flight that cannot avoid the trap have been included in this analysis. However for 15 of the taxa that were captured in the traps we found no significant ecotone effect (Table 1). For those species that did not respond to ecotone we conclude that the ecotone did not represent a significant barrier to movement as compared to crop/crop interfaces. These species, such as Nysius vinitor (Rutherglen bug) and Micromus sp. are known to use resources in multiple habitat-types in these landscapes and will therefore not necessarily show strong movement patterns in relation to NV patches. For those taxa that showed a significant ecotone effect, we found a range of movement responses to ecotone. Previous studies have shown that species response to ecotone can be idiosyncratic (Perovic and Gurr, 2012). Here we found that Microgastrinae parasitoids moved more commonly across the crop/crop interface than across the ecotone. In contrast, Aphidiinae parasitoids moved more often from NV into crops than between crops.

The analysis at the functional group level indicated that predators preferentially moved out of NV early in the season, whereas at the taxon level only few predator species showed significant responses to ecotone (Table 1; but see Melangyna for an exception). We further explored the influence of Melangyna on the predator functional group by removing this taxon and re-running the models, however, this did not alter the outcome. This suggests that the functional group result may be caused by the cumulative movement patterns of many predatory taxa and not necessarily a single dominant taxon.

\subsection{Regional differences}

Considering the large differences between the two regions in terms of cropping strategies, landscape features, weather conditions and pest management strategies, it is notable that we found consistent patterns in insect movement patterns from NV across these regions. Once we standardised for differences in crop development (using AGDD) there were few taxa that showed a significant interaction between ecotone and region (Table 1; but see Aphidiinae spp. for an exception). There were, however, regional differences in the number of individuals moving, regardless of ecotone. For example, Micromus sp. showed no ecotone effect, but was significantly more abundant in the samples in NSW than in QLD.

\section{Acknowledgements}

Many thanks go to the land holders for allowing us access to their properties. We especially thank Nick Nicholls for his statistical support and advice about the analysis. This work was funded by the Grains Research and Development Corporation as part of the Pest Suppressive Landscapes project (CSE00051). The project team included the authors and Svetlana Micic, Art Diggle, Mike Grimm, Tony Dore (DAFWA), Paul Yeoh, Andrew Hulthen (CSIRO), Zara Hall, Adam Quade, and Matt Davis (DAFFQ). The aphid identifications were checked by Cameron Brumley (DAFWA). The raw and derived data sets can be accessed from Macfadyen et al. (2013). 


\section{Appendix A. Supplementary data}

Supplementary data associated with this article can be found, in the online version, at http://dx.doi.org/10.1016/j.agee.2014.11.012.

\section{References}

Al Hassan, D., Georgelin, E., Delattre, T., Burel, F., Plantegenest, M., Kindlmann, P., Butet, A., 2013. Does the presence of grassy strips and landscape grain affect the spatial distribution of aphids and their carabid predators? Agric. For. Entomol. $15,24-33$.

Alomara, O., Goulab, M., Albajesc, R., 2002. Colonisation of tomato fields by predatory mirid bugs (Hemiptera: Heteroptera) in northern Spain. Agric. Ecosyst. Environ. 89, 105-115.

Anderson, M.J., Gorley, R.N., Clarke, K.R., 2008. PERMANOVA+ for PRIMER: Guide to software and statistical methods. PRIMER-E, Plymouth, UK.

Bailey, P.T., 2007. Pests of Field Crops and Pastures. Identification and Control. CSIRO Publishing, Collingwood, Australia.

Bennett, A.B., Gratton, C., 2012. Measuring natural pest suppression at different spatial scales affects the importance of local variables. Environ. Entomol. 41, 1077-1085.

Bianchi, F.J.J.A., Schellhorn, N.A., Buckley, Y.M., Possingham, H.P., 2010. Spatial variability in ecosystem services: simple rules for predator-mediated pest suppression. Ecol. Appl. 20, 2322-2333.

Bianchi, F.J.J.A., Schellhorn, N.A., Cunningham, S.A., 2012. Habitat functionality for the ecosystem service of pest control: reproduction and feeding sites of pests and natural enemies. Agric. For. Entomol. 12-23.

Bianchi, F.J.J.A., Schellhorn, N.A., van der Werf, W., 2009. Predicting the time to colonization of the parasitoid Diadegma semiclausum: the importance of the shape of spatial dispersal kernels for biological control. Biol. Control 50, 267-274.

Bolker, B., Brooks, M.E., Clark, C.J., Geange, S.W., Poulsen, J.R., Stevens, M.H.H., White, J.S., 2009. Generalized linear mixed models: a practical guide for ecology and evolution. Trends Ecol. Evol. 24, 127-135.

Bolker, B.A., Brooks, M.E., Clark, C.J., Geange, S.W., Poulsen, J.R., Stevens, M.H.H., White, J.S., 2011. GLMMs in action: gene-by-environment interaction in total fruit production of wild populations of Arabidopsis thaliana Revised version, part 2. (available at www.cell.com/cms/attachment/601623/4742453/mmc2. pdf).

Caballero-López, B., Bommarco, R., Blanco-Moreno, J.M., Sans, F.X., Pujade-Villar, J., Rundlöf, M., Smith, H.G., 2012. Aphids and their natural enemies are differently affected by habitat features at local and landscape scales. Biol. Control 63, 222-229.

Campbell, R.E., Harding, J.S., Ewers, R.M., Thorpe, S., Didham, R.K., 2011. Production land use alters edge response functions in remnant forest invertebrate communities. Ecol. Appl. 21, 3147-3161.

Chang, G.C., Kareiva, P., 1999. The case of indigenous generalists in biological control. In: Cornell, H.V. (Ed.), Theoretical Approaches to Biological Control. Cambridge University Press, Cambridge.

Chaplin-Kramer, R., Kremen, C., 2012. Pest control experiments show benefits of complexity at landscape and local scales. Ecol. Appl. 22, 1936-1948.

Clark, K.R., Gorley, R.N., 2006. PRIMER v6: User Manual/Tutorial. PRIMER-E, Plymouth, UK.

Cronin, J.T., Reeve, J.D., 2005. Host-parasitoid spatial ecology: a plea for a landscapelevel synthesis. Proc. R. Soc. Lond. Ser. B Biol. Sci. 272, 2225-2235.

Cunningham, S.A., Schellhorn, N.A., Marcora, A., Batley, M., 2013. Movement and phenology of bees in a subtropical Australian agricultural landscape. Austral Ecol. 38 (4), 456-464.

Duelli, P., Obrist, M.K., 2003. Regional biodiversity in an agricultural landscape: the contribution of seminatural habitat islands. Basic Appl. Ecol. 4, 129-138.

Duelli, P., Studer, M., Marchand, I., Jakob, S., 1990. Population movements of arthropods between natural and cultivated areas. Biol. Conserv. 54, 193-207.

Ekbom, B.S., Wiktelius, S., Chiverton, P.A., 1992. Can polyphagous predators control the bird cherry-oat aphid (Rhopalosiphum padi) in spring cereals - a simulation study. Entomol. Exp. Appl. 65, 215-223.
Fox, J., Weisberg, S., 2011. An R Companion to Applied Regression. Sage, Thousand Oaks, CA.

Irwin, M.E., Nault, L.R., Godoy, C., Kampmeier, G.E., 2000. Diversity and movement patterns of leaf beetles (Coleoptera: Chrysomelidae) and leafhoppers (Homoptera: Cicadellidae) in a heterogenous tropical landscape. Implications for redressing the Integrated Pest Management paradigm. In: Ekbom, B., Irwin, M.E., Robert, Y. (Eds.), Interchanges of Insects Between Agricultural and Surrounding Landscapes. Springer, pp. 141-168.

Isaacs, R., Tuell, J., Fiedler, A., Gardiner, M., Landis, D., 2009. Maximizing arthropodmediated ecosystem services in agricultural landscapes: the role of native plants. Front. Ecol. Environ. 7, 196-203.

Ives, A.R., Settle, W.H., 1997. Metapopulation dynamics and pest control in agricultural systems. Am. Nat. 149, 220-246.

Kremen, C., 2005. Managing ecosystem services: what do we need to know about their ecology? Ecol. Lett. 8, 468-479.

Letourneau, D.K., Allen, S.G.B., Stireman, J.O., 2012. Perennial habitat fragments, parasitoid diversity and parasitism in ephemeral crops. J. Appl. Ecol. 49, 1405-1416.

Macfadyen, S.,Hopkinson, J., Parry, H., Neave, M., Bianchi, F.J.J.A., Zalucki, M.P., Schellhorn, N.A. (2013): Early-season movement dynamics of phytophagous pest and natural enemies across a native vegetation-crop ecotone. v1. CSIRO. Data Collection. http://dx.doi.org/10.4225/08/546AB0229BDE8.

Macfadyen, S., Muller, W., 2013. Edges in agricultural landscapes: species interactions and movement of natural enemies. PLoS One 8, e59659.

McMaster, G.S., 1997. Phenology, development, and growth of the wheat (Triticum aestivum L.) shoot apex: A review. In: Donald, L.S. (Ed.), Advances in Agronomy. Academic Press, pp. 63-118.

Mesa, L.A., Howlett, B.G., Grant, J.E., Didham, R.K., 2013. Changes in the relative abundance and movement of insect pollinators during the flowering cycle of Brassica rapa crops: implications for gene flow. J. Insect Sci. 13, 13.

Perovic, D.J., Gurr, G.M., 2012. Geostatistical analysis shows species-specific habitat preferences for parasitoids. Biocontrol Sci. Technol. 22, 243-247.

Petersen, M.K., 1999. The timing of dispersal of the predatory beetles Bembidion lampros and Tachyporus hypnorum from hibernating sites into arable field. Entomol. Exp. Appl. 90, 221-224.

Rand, T.A., Tylianakis, J.M., Tscharntke, T., 2006. Spillover edge effects: the dispersal of agriculturally subsidized insect natural enemies into adjacent natural habitats. Ecol. Lett. 9, 603-614.

Ries, L., Debinski, D.M., 2001. Butterfly responses to habitat edges in the highly fragmented prairies of Central Iowa. J. Anim. Ecol. 70, 840-852.

Schellhorn, N.A., Macfadyen, S., Bianchi, F.J.J.A., Williams, D.G., Zalucki, M.P., 2008 Managing ecosystem services in broadacre landscapes: what are the appropriate spatial scales? Aust. J. Exp. Agric. 48, 1549-1559.

Settle, W.H., Hartjahyo, A., Astuti, E.T., Widyastama, C., Arief Lukman, H., Dadan, H., Alifah Sri, L., 1996. Managing tropical rice pests through conservation of generalists natural enemies and alternative prey. Ecology 77, 1975-1988.

Sivakoff, F.S., Rosenheim, J.A., Hagler, J.R., 2012. Relative dispersal ability of a key agricultural pest and its predators in an annual agroecosystem. Biol. Control 63 296-303.

Southwood, T.R.E., Hendersen, P.A., 2000. Ecological Methods. Blackwell Science, Oxford.

Stephens, C.J., Schellhorn, N.A., Wood, G.M., Austin, A.D., 2006. Parasitic wasp assemblages associated with native and weedy plant species in an agricultural landscape. Aust. J. Entomol. 45, 176-184.

Thomson, L.J., Hoffmann, A.A., 2013. Spatial scale of benefits from adjacent woody vegetation on natural enemies within vineyards. Biol. Control 64, 57-65.

Van Emden, H.F., 1965. The role of uncultivated land in the biology of crop pests and beneficial insects. Sci. Hortic. 17, 121-136.

Vollhardt, I.M.G., Tscharntke, T., Wäckers, F.L., Bianchi, F.J.J.A., Thies, C., 2008 Diversity of cereal aphid parasitoids in simple and complex landscapes. Agric. Ecosyst. Environ. 126, 289-292.

Wissinger, S.A., 1997. Cyclic colonization in predictably ephemeral habitats: a template for biological control in annual crop systems. Biol. Control 10, 4-15.

Zhang, W., Ricketts, T.H., Kremen, C., Carney, K., Swinton, S.M., 2007. Ecosystem services and dis-services to agriculture. Ecol. Econ. 64, 253-260. 